\title{
Estudando os anfíbios por meio de atividades lúdicas
}

\section{Studying amphibians through playful activities}

\author{
Susana Weyh Wammes (susanawammes@gmail.com) \\ Universidade Federal da Fronteira Sul - UFFS
}

\begin{abstract}
Resumo: Este trabalho corresponde a um relato de experiência referente a uma aula desenvolvida no $7^{\circ}$ ano do ensino fundamental no ano de $2017 \mathrm{em}$ uma escola vinculada ao Programa Institucional de Bolsas de Iniciação a Docência - PIBID. Está escrita relata as vivências da sala de aula, na qual busco compartilhar com os demais colegas licenciandos, professores da escola básica e professores formadores, um dos primeiros contatos individuais quanto ao planejamento e execução de uma aula. O assunto desta aula foi anfíbios e a metodologia de ensino utilizada foi aula expositiva/dialogada, áudios de vocalização, jogo de perguntas em grupos, questionário objetivo e demonstração de um aplicativo de smartphone de dissecação. O resultado desta aula foi bastante satisfatória, pois os alunos demostraram interesse e curiosidade, foram participativos e a partir das atividades desenvolvidas, mostraram resultados de aprendizagem. A partir do desenvolvimento desta aula, pude perceber o que é necessário melhorar para uma próxima vez e o que transcorreu positivamente e pode ser mantido. Foi uma experiência muito boa porque praticamente tudo ocorreu na medida do planejado, ainda mais levando em conta que foi a primeira aula desenvolvida individualmente.
\end{abstract}

Palavras-chave: Pibid; Atividades lúdicas; Anfíbios.

Abstract: This work corresponds to an experience report referring to a class developed in the 7th grade of elementary school in 2017 in a school linked to the Institutional Teaching Scholarship Program - PIBID. This writing relates the experiences of the classroom, in which I seek to share with other fellow undergraduates, primary school teachers and teacher trainers, one of the first individual contacts regarding the planning and execution of a class. The subject of this class was amphibians and the teaching methodology used was expository/dialogue class, vocalization audios, group questioning game, objective questionnaire and demonstration of a smartphone application for dissection. The result of this class was very satisfactory, because the students showed interest and curiosity, were participatory and from the activities developed, showed learning outcomes. From the development of this class, I could see what needs to be improved for the next time and what happened positively and can be maintained. It was

Recebido em: 27/08/2019 


\section{Vol. 2, n. 3 - Edição Especial: Ciclos Formativos em Ensino de Ciências.}

a very good experience because practically everything happened as planned, even more so taking into account that it was the first class developed individually.

Keywords: Pibid; Playful activities; Amphibians.

\section{INTRODUÇÃO}

Em uma das atividades propostas no Programa Institucional de Bolsas de Iniciação à Docência (PIBID), tive a oportunidade de planejar e desenvolver uma aula sobre a temática anfíbios dentro da área de ciências para os alunos do $6^{\circ}$ ano do ensino fundamental da escola a qual estava inserida no ano de 2017.

O PIBID tem por finalidade, permitir que o estudante licenciando em formação inicial, entre em contato com a sala de aula antes dos estágios, preparando-o para a realidade profissional e seus desafios. O papel dos licenciandos bolsistas deste programa, é auxiliar o professor da escola básica no desenvolvimento de suas aulas através do planejamento de atividades diferenciadas. $\mathrm{Na}$ área de ciência, o enfoque é principalmente no desenvolvimento de aulas experimentais. No entanto, como sabemos, nem sempre é possível contemplar este recurso didático e propor uma aula laboratorial para exatamente todos os conteúdos. Além disso, precisamos levar em conta que, em muitas escolas, os laboratórios de ciências não possuem estrutura e materiais sofisticados, e a maioria dos professores não têm tempo para planejar atividades assim.

Levando em consideração todos estes fatores, somados a indisciplina, falta de interesse e dificuldades de aprendizagem por parte dos alunos, é importante a colaboração dos bolsistas em trazerem propostas de atividades que buscam minimizar estes fatores negativos, fazendo com que os alunos tenham mais de interesse pelo assunto em estudo. Como destaca Pedroso (2009) "as atividades lúdicas, como as brincadeiras, os brinquedos e os jogos, são reconhecidos pela sociedade como meio de fornecer ao individuo um ambiente agradável, motivador, prazeroso, planejado e enriquecido, que possibilita a aprendizagem de várias habilidades" (PEDROSO, 2009, p. 3183). Portanto, é positivo 


\section{Vol. 2, n. 3 - Edição Especial: Ciclos Formativos em Ensino de Ciências.}

para o processo de ensino e aprendizado o trabalho a partir de atividades didáticas diferenciadas.

A utilização de recursos didáticos diferenciados e lúdicos tem um papel de estimular os alunos a querer aprender determinado assunto e reforçar conteúdos já estudados, fazendo com que os alunos tenham uma maior aprendizagem e capacidade de compreensão do tema (OLIVEIRA et al., 2014).

No entanto, para que o uso de recursos didáticos variados sejam capazes de produzir aprendizagens significativas, é crucial que o preparo do professor, pois o mesmo precisa saber distinguir e selecionar os tipos de atividades que mais contribuem para a aprendizagem de seus alunos, precisando ter também criatividade de desenvolver novos recursos, buscar atividades e moldá-las de acordo com o nível de ensino, saber explorar cada recurso de maneira positiva e construtiva (SILVA et al., 2012). Para tal, cabe destacar já de antemão a importância da formação inicial e continuada através de programas oferecidos pelo governo, que buscam qualificar e aperfeiçoar os professores e o ensino.

Nesta perspectiva, também é conveniente a disponibilização destes recursos didáticos por parte da escola (SOUZA, 2007), pois se torna mais viável o desenvolvimento de aulas diversificadas. A falta de materiais, aliás, é uma das barreiras que desmotivam os professores, principalmente na área de ciências.

Tendo em vista que, o uso de atividades mais dinâmicas e diferenciadas contribuem no sentido de motivar os alunos no processo de ensino e aprendizagem, foi planejada uma aula que envolvesse atividades para além de uma exposição do conteúdo, como ainda é fortemente feito pelos professores, objetivando uma melhor compreensão e aprendizagem por parte dos alunos. Estas atividades foram pensadas dentro das possibilidades encontradas como, tempo de aula, estrutura do laboratório, materiais, recursos tecnológicos disponíveis pela escola e dos alunos, nível de aprendizagem da turma, tamanho da turma, etc. 


\section{Vol. 2, n. 3 - Edição Especial: Ciclos Formativos em Ensino de Ciências.}

Nesta perspectiva, destacamos que para a escolha das atividades a serem realizadas, é fundamental o conhecimento prévio por parte do professor tanto da realidade da escola quanto dos alunos. Assim, quando as aulas são desenvolvidas por alunos pibidianos, é importante o diálogo com o professor da turma e também a observação de aulas antes de iniciar as atividades, assim como é solicitado no programa de iniciação a docências Pibid.

Desta forma, este relato tem a finalidade de descrever a aula desenvolvida com os alunos, apresentar resultados, interpretá-los na medida do possível, compartilhar minha percepção de um modo geral sobre a mesma, falar de como me senti e da experiência que tive com esta atividade contribuindo de forma positiva na minha formação.

\section{METODOLOGIA}

Para o desenvolvimento desta aula de dois períodos (totalizando 1 h e $40 \mathrm{~min}$ ), no qual primeiramente foi realizada uma aula mais expositiva/dialogada sobre o tema anfíbios, com apresentação em PowerPoint baseado na leitura de materiais disponibilizados por um professor da universidade, livro didático da turma e na internet. Desta forma, nesta apresentação foi abordado a evolução dos anfíbios, classificação, principais características, ambiente de vida, reprodução, importância e outras peculiaridades. Foi ainda reproduzido a vocalização de alguns anuros e mostradas fotos de algumas espécies presentes no município de Cerro Largo (RS) e Roque Gonzales (RS) para conhecimento e valorização da biodiversidade local.

Em um segundo momento, foi realizado uma atividade de perguntas e respostas para relembrar e aprimorar os assuntos estudados. Para esta atividade os alunos formaram dois grupos. No quadro foram coladas com fita durex, folhas de ofício enumeradas de 1 a 15 que continham no verso uma questão referente à temática estudada. Cada grupo deveria escolher um número e responder a pergunta que estava no verso. Para cada pergunta respondida corretamente o grupo pontuava um ponto. Assim, ao final, vence o grupo que obtiver o maior somatório de pontos. Ao final do jogo, foi realizado um questionário individual para perceber a aprendizagem particular de cada aluno.

Recebido em: 27/08/2019 


\section{Vol. 2, n. 3 - Edição Especial: Ciclos Formativos em Ensino de Ciências.}

A proposta para uma última atividade, foi a demonstração de um aplicativo de smartphone (Dissection Lab) que simula virtualmente a dissecação de um sapo, ou seja, a abertura de um sapo para visualizar a estruturação interna deste animal e conhecer o nome e localização de cada órgão. Esta proposta vem no intuito de inserção das tecnologias na sala de aula e substituição da metodologia prática que necessita sacrificar o animal.

\section{RESULTADOS E DISCUSSÃO}

Referente à parte inicial da aula, que foi mais expositiva (Figura 1), pude notar que os alunos prestavam muita atenção no que eu falava, respondiam as perguntas que lançava e quando algo lhes chamava a atenção ou causava dúvida, eles perguntavam. Acredito que a ordem que se manteve na classe se deu pelo motivo de uma pessoa desconhecida estar ministrando a aula, ou seja, eles se sentiram intimidados. Já o interesse, mesmo na aula expositiva que por vezes se torna algo monótona e cansativa, se deu provavelmente pelo assunto ser condizente com o que eles já conhecem e vivenciam no cotidiano e pelas características curiosas deste grupo de animais. Ou também, o comportamento pode ser justificado pelo fato de ser uma aula diferente, com apresentação de slides, que normalmente não é feito nas aulas tradicionais.

Figura 1 - Explicação sobre o ciclo de vida dos anuros em uma aula do $6^{\circ}$ ano de uma escola de Cerro Largo em 2017.

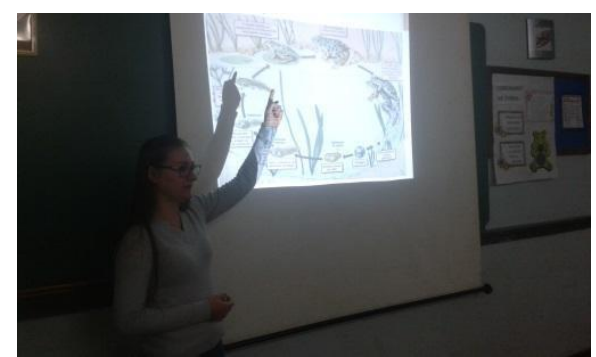

Fonte: Elaborado pelo autor, 2017.

Com a realização do jogo de perguntas (Figura 2) que colocava em prática as aprendizagens adquiridas, foi possível verificar que dentre as 15 questões somente 1 não foi respondida corretamente. Este resultado dá a entender que os alunos tiveram um 


\section{Vol. 2, n. 3 - Edição Especial: Ciclos Formativos em Ensino de Ciências.}

entendimento do assunto como o esperado. Eles se mostravam interessados e desafiados durante a realização desta atividade, porque com certeza era algo novo para eles. Já referente ao questionário individual pude perceber que tiveram um pouco mais de dificuldades.

Figura 2 - Montagem do jogo das perguntas sobre anuros em uma aula do $6^{\circ}$ ano de uma escola de Cerro Largo em 2017.

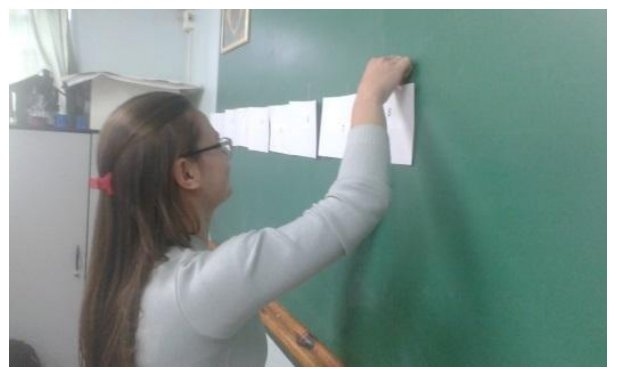

Fonte: Elaborado pelo autor, 2017.

$\mathrm{Na}$ amostragem do aplicativo (Figura 3) ficou explícito o encantamento dos alunos, no entanto, eles não puderam verificar pessoalmente naquele momento devido a proibição do uso do celular na sala de aula. Por mais que o uso de tecnologias seja defendido pelas Diretrizes Curriculares Nacionais de Educação, a liberação do uso de celulares ou objetos semelhantes na sala de aula é um assunto muito delicado, tendo em vista os transtornos que causam no caso do uso inadequado. Sendo assim, na maioria das escolas da região que se tem conhecimento, o uso do celular dentro da sala de aula é proibido, principalmente porque os alunos não possuem maturidade e comprometimento para usá-lo como ferramenta de aprendizagem.

Figura 3 - Aplicativo Dissection Lab no Play Store.

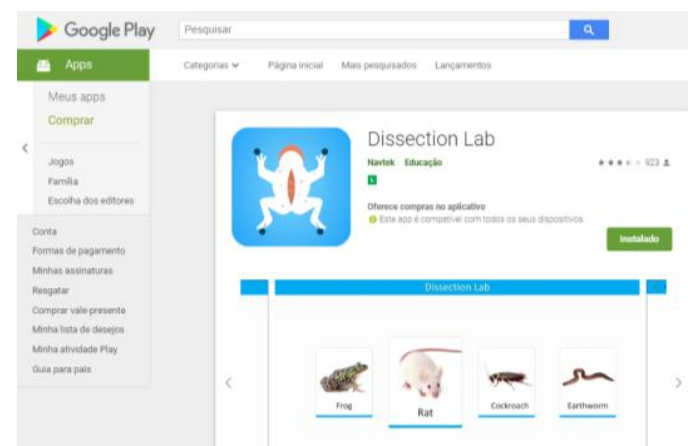

Fonte: Play Store, 2019.

Recebido em: 27/08/2019 


\section{Vol. 2, n. 3 - Edição Especial: Ciclos Formativos em Ensino de Ciências.}

Por outro lado, quando as tecnologias mais recentes são utilizadas com o propósito de melhorar o ensino-aprendizagem dos alunos, elas são muito bem vindas. Como salienta Ramos (2012, p. 4) “A tecnologia surge para facilitar a vida humana e seus afazeres”. No entanto, a proposta do uso do celular na sala parece inviável, pelo menos por enquanto, porque é preciso ter todo um replanejamento do projeto educacional. Sem contar que é de suma importância considerar a realidade de grande parte das nossas escolas públicas e das condições financeiras das famílias dos nossos alunos, pois as tecnologias mais recentes (smartphone, TV e som com entrada para pendriv, etc) nem sempre são acessíveis.

$\mathrm{Na}$ atualidade existem vários aplicativos que podem ser usados na sala de aula para contribuir na aprendizagem, como por exemplo, o Kahhot que consiste em um game de questões e pode ser usado como um método de avaliação de ensino (SILVA, 2018). É uma ferramenta bastante interessante, porém necessita de aparelhos individuais e uma rede de internet de boa qualidade. Ou seja, não é em todo contexto escolar que é possível utilizá-lo, por isto, na aula desenvolvida, foi confeccionado uma atividade envolvendo questionário de uma forma mais simples sem tecnologias, mas de uma maneira não convencional.

\section{CONCLUSÃO}

A partir do desenvolvimento desta aula pude experimentar um pouco sobre como é ser professor, como é planejar e colocar em prática uma aula, como é interagir com os alunos, mantê-los atentos, despertar o interesse, tirar dúvidas, pedir silêncio, entre outras coisas que caracterizam a dinâmica da sala de aula.

De um modo geral, fiquei bem satisfeita com o resultado obtido e percebi que os alunos também ficaram mais eufóricos. Sendo assim, valeu a pena toda a dedicação colocada em cima do planejamento da aula e confecção do jogo. Acredito que por meio de aulas e atividades como estas que são diferentes do padrão, podemos motivar mais os alunos e fazer com que aprendam de uma forma descontraída. 


\section{Vol. 2, n. 3 - Edição Especial: Ciclos Formativos em Ensino de Ciências.}

Neste sentido reforço a relevância dos programas como o de formação inicial de professores (PIBID), que além de fazer esta parceria com as escolas e permitir o contato e experiência do licenciando desde cedo com este contexto, proporciona momentos de formação que permitem refletir sobre a prática docente e construir concepções novas sobre o ensino.

A partir da execução de uma aula, é possível refletir sobre ela e propor o que poderia ter sido feito diferente e o que foi positivo. Por exemplo, uma proposta interessante que cabe ao tema trabalhado, seria fazer o acompanhamento do desenvolvimento dos anfíbios em laboratório, no qual os alunos poderiam observar o processo de metamorfose com o passar do tempo. Com esta atividade poderiam ser desenvolvidos no aluno, algumas etapas da experimentação, como a observação, que é importante na construção do conhecimento científico.

\section{REFERÊNCIAS}

OLIVEIRA, A. M. V.. Produção de material didático para o ensino de biologia: uma estratégia desenvolvida pelo PIBID/Biologia/FECLI. REnBio, Niterói, 7 ed. p. 682-691, out. 2014. Disponível em: <http://docplayer.com.br/11488460-Producao-de-materialdidatico-para-o-ensino-de-biologia-uma-estrategia-desenvolvida-pelo-pibid-biologiafecli.html>. Acesso em: 26 abr. 2019.

PEDROSO, Carla Vargas. Jogos didáticos no ensino de biologia: uma proposta metodológica baseada em módulo didático. In: ANAL DE IX CONGRESSO NACIONAL DE EDUCAÇÃO (EDUCERE) \& III ENCONTRO SUL BRASILEIRO DE PSICOPEDAGOGIA. Anais [...] Paraná, 2009. p. 3182-3190. Disponível em: <http://educere.bruc.com.br/arquivo/pdf2009/2944_1408.pdf>. Acesso em: 02 nov. 2018.

RAMOS, Márcio Roberto Vieira. O uso de tecnologias em sala de aula. Ensino de Sociologia em Debate. Londrina, 2 ed. v. 1, p. 1-16, jul-dez 2012. Disponível em: <http://www.uel.br/revistas/lenpespibid/pages/arquivos/2\%20Edicao/MARCIO\%20RA MOS\%20-\%20ORIENT\%20PROF\%20ANGELA.pdf>. Acesso em: 26 nov. 2018.

SILVA, Maria Cristina da Pamplona. USO DO KAHOOT! COMO FERRAMENTA DE AVALIAÇÃO E ENSINO-APRENDIZAGEM NO ENSINO DA MEMBRANA PLASMÁTICA. Estácio Saúde, Santa Catarina, v. 7, n. 2, p.06-09, jan. 2018. Disponível em:

Recebido em: 27/08/2019 
Vol. 2, n. 3 - Edição Especial: Ciclos Formativos em Ensino de Ciências.

<http://periodicos.estacio.br/index.php/saudesantacatarina/article/viewFile/5434/479649 40>. Acesso em: 29 abr. 2019.

SILVA, Maria do Amparo dos Santos et al. Utilização de Recursos Didáticos no processo de ensino e aprendizagem de Ciências Naturais em turmas de $8^{\circ}$ e $9^{\circ}$ anos de uma Escola Pública de Teresina no Piauí. In: CONGRESSO NORTE-NORDESTE DE PESQUISA E INOVAÇÃO. Ciência, tecnologia e inovação: Ações Sustentáveis para o desenvolvimento regional. Tocantins, 2012. p. 1 - 6. Disponível em: <http://propi.ifto.edu.br/ocs/index.php/connepi/vii/paper/viewFile/3849/2734>. Acesso em: 29 abr. 2019.

SOUZA, Salete Eduardo. O uso de recursos didáticos no ensino escolar. In: I ENCONTRO DE PESQUISA EM EDUCAÇAO, IV JORNADA DE PRÁTICA DE ENSINO, XIII SEMANA DE PEDAGOGIA DA UEM: INFANCIA E PRÁTICAS EDUCATIVAS. Anais [...] Maringá, PR, 2007. Disponível em <http://www.dma.ufv.br/downloads/MAT\%20103/2015-

II/slides/Rec\%20Didaticos\%20-\%20MAT\%20103\%20-\%202015-II.pdf>. Acesso em: 26 abr. 2019.

Recebido em: 27/08/2019 